\title{
Main Pancreatic and Accessory Ducts
}

National Cancer Institute

\section{Source}

National Cancer Institute. Main Pancreatic and Accessory Ducts. NCI Thesaurus. Code C154699.

Any of the ducts that conveys pancreatic secretions from the pancreas to the duodenum. 